\title{
Pregnancy after Breast Cancer: Myths and Facts
}

\author{
Olivia Pagani ${ }^{\mathrm{a}}$ Hatem Azim Jr. ${ }^{\mathrm{b}}$ \\ anstitute of Oncology of Southern Switzerland, Breast Unit of Southern Switzerland, Ospedale san Giovanni, Bellinzona, Switzerland \\ ${ }^{b}$ Breast Cancer Translational Research Laboratory and Department of Medical Oncology, Institut Jules Bordet, Université Libre de \\ Bruxelles, Brussels, Belgium
}

\section{Keywords \\ Breast cancer · Breastfeeding · Pregnancy}

\section{Summary}

Most young breast cancer survivors consider reproductive issues to be of great importance, but many questions remain undervalued and unanswered. Overall, available data support the safety and feasibility of pregnancy and breastfeeding after breast cancer. The accuracy of the evidence is however limited by: i) the retrospective and frequently incomplete population-based nature of the data, ii) data not representing the entire population, iii) patient-related effects, iv) underpowered sample size, and v) lack of control for biological factors and risk determinants. We review the available evidence in light of these limitations which outline the need for prospective data collection and focused priority research.

\section{Introduction}

Breast cancer (BC) in young women represents a complex scenario with many unmet disease-related and psycho-social needs. Approximately 7\% of BC patients are diagnosed at age $<40$ years, around $3 \%<35$ years, and $1 \%<30$ years. Overall, BC accounts for over $40 \%$ of all cancers in women of this age group [1]. Improvements in early diagnosis and adjuvant treatment have led to a constant decrease in death rates (3.8\%/year among women $<50$ years versus $2.2 \%$ /year among women $\geq 50$ years) [2]. As a consequence, around 300,000400,000 young BC survivors were estimated in the US in 2011. On the other hand, there is an increasing trend towards delaying pregnancy all over the world [3-6]. The proportion of first-time mothers aged $\geq 30$ years has increased in the US since the early 1990 s from 4.1 to $21.2 \%$ [7, 8]. Consequently, a

\section{Schlüsselwörter \\ Mammakarzinom · Stillen · Schwangerschaft}

\section{Zusammenfassung}

Für die meisten jungen Brustkrebsüberlebenden sind reproduktive Belange von großer Wichtigkeit. Dennoch werden viele Fragen weiterhin unterschätzt und bleiben unbeantwortet. Die verfügbaren Daten unterstützen im Allgemeinen die Sicherheit und Durchführbarkeit von Schwangerschaft und Stillen nach Brustkrebs. Die Genauigkeit der wissenschaftlichen Daten ist jedoch limitiert durch: i) die retrospektive und oft unvollständige, bevölkerungsbezogene Natur der Daten, ii) fehlende Repräsentation der Gesamtbevölkerung, iii) patientenbezogene Einflüsse, iv) unzureichende Fallzahlen, und v) fehlende Berücksichtigung biologischer Faktoren und Risiko-Determinanten. Wir beleuchten die vorliegende Literatur mit Bezug auf diese Limitationen, welche den Bedarf an prospektiver Datenakkumulation und fokussierter Schwerpunktforschung aufzeigen.

growing number of patients face $\mathrm{BC}$ before completion of their reproductive plans.

\section{Is Pregnancy after Breast Cancer Common?}

The desired number of children has decreased in recent decades. Fertility surveys in the general population show that most people still want children, but, given the current socioeconomic and cultural circumstances, no more than 1 or 2 [911]. Less than $10 \%$ of women with previous BC subsequently become pregnant [12-15]. This is around half the pregnancy rate seen in age-matched groups without $\mathrm{BC}[16,17]$. Women with $\mathrm{BC}$ are also more likely to have a live birth at an older age than the general population because of their cancer treatment. Of note, the vast majority of available data rely on

\section{KARGER}

Fax +497614520714

Information@Karger.de

www.karger.com (c) 2012 S. Karger GmbH, Freiburg

$1661-3791 / 12 / 0073-0210 \$ 38.00 / 0$

Accessible online at:

www.karger.com/brc
Dr. Olivia Pagani

Institute of Oncology of Southern Switzerland

Breast Unit of Southern Switzerland

Ospedale san Giovanni

6500 Bellinzona, Switzerland

opagani@bluewin.ch 
patients who were disease-free at the time of pregnancy. Very little is known regarding pregnancy in women who relapse after the initial diagnosis. It is likely to be uncommon and remains a taboo and an undiscovered world.

\section{What Do Young Patients with Breast Cancer Think and Fear about Subsequent Pregnancy?}

BC patients who have not started or completed their families may wish to consider pregnancy following treatment but they may worry about whether or not it is safe [18]. A qualitative study in 23 women who had children after BC reported that the possibility of becoming pregnant was a powerful stimulus to 'get well' but also outlined concerns about the potential for future disease recurrence and about surviving to see their children grow up [19]. 657 of 1,702 patients belonging to the Young Survival Coalition completed a web survey which is the largest dataset available so far [18]. 29\% of women indicated that concerns about fertility influenced their treatment decisions. In a multivariate analysis, greater and significant concern was associated with the wish for children/more children, number of prior pregnancies, and prior difficulty conceiving. Of note, 309 (47\%) women reported they did not want a future biologic child or were unsure; of those, $36 \%$ thought a future pregnancy would increase their risk of recurrence, $48 \%$ did not think it would, and $16 \%$ were unsure. Another recent qualitative survey [20] in 20 young BC survivors - half of whom had a child after diagnosis - showed that participants that valued fertility and expected to have children in the future were more likely to have weighed up fertility issues when making their treatment decisions. Participants' primary motivations for treatment decisions were nonetheless improved survival and reduced risk of recurrence.

Overall, all these data have several limitations: i) the sample size is generally small and retrospective; ii) the population is not representative of all young women with BC, as most subjects are Caucasian with a college degree; iii) data rely on women recalling their experiences, not taking into account health and psychosocial changes over time. In principle, young women with $\mathrm{BC}$ are more likely to experience anxiety and distress which usually diminish over time, indicating that young women can adapt. A longitudinal study collected depressive symptoms data over approximately 10 years in 131 young patients with BC participating in the WHEL study. This is a multicenter randomized controlled trial evaluating the effectiveness of a high-vegetable, low-fat diet to reduce recurrence of $\mathrm{BC}$ and early death [21]. Concerns about reproduction after treatment contributed to long-term depressive symptoms, even after controlling for social support and physical health. The multivariate analysis found no significant difference among women who had children compared to those who did not and to those who had a child after BC. Similar results were observed in another study conducted in an ethnically diverse sample of 331 young women with newly diagnosed BC [22].

\section{Do Health Professionals Address Fertility Issues?}

Young BC patients have specific fertility needs and concerns which are commonly not adequately addressed or discussed prior to commencing adjuvant therapy. There is limited research about both patients' fertility-related needs and attitudes of health care providers, and few tools available to assist with fertility-related decisions [23, 24]. However available evidence points out that abortion is frequently recommended by physicians for fear that pregnancy could stimulate $\mathrm{BC}$ recurrence [25]. In an individual trial, around $30 \%$ of women decided to abort as suggested by their treating physicians [26], highlighting the need for robust evidence to guide physicians in proper counseling of their patients.

In an exploratory substudy of a cross-sectional trial evaluating ovarian reserves in young $\mathrm{BC}$ survivors compared with controls, women $\leq 40$ years seemed more concerned about fertility-related issues than age- and gravidity-matched controls, even when only women who desired a future child were analyzed [27].

The results of the survey conducted by the Breast International Group (BIG) in 389 very young patients $(<35$ years) with early $\mathrm{BC}$ from several countries and with different sociocultural attitudes, show that a substantial proportion of patients wanted more future children. Interestingly, among the ones who did not, almost $40 \%$ were afraid of tumor recurrence (paper submitted). Prospective data are also being collected through a joint international initiative (Helping Ourselves, Helping Others HOHO: The Young Women's Breast Cancer Study). Preliminary results from 85 patients of the European cohort show that $45 \%$ of subjects had no children before the $\mathrm{BC}$ diagnosis, and $41 \%$ wish to consider pregnancy after BC treatment; of those, $69 \%$ had no history of previous pregnancy.

\section{Is Pregnancy after Breast Cancer Safe?}

\section{For the Baby?}

There is no evidence that pregnancy in BC survivors is associated with any risk to the infant's health. Data from 2 large population-based cohort studies are rather reassuring in this regard [28, 29]. However in the Swedish cohort, an increased risk of delivery complications, caesarean section, very preterm birth ( $<32$ weeks), and low birth weight $(<1,500 \mathrm{~g})$ were reported compared to healthy controls. These findings have potential implications for vigilant pregnancy surveillance and management in this population. Taking into account the time of oocyte maturation, it is recommended to wait for at least 6 months from the end of chemotherapy before becoming 
pregnant. For patients receiving endocrine therapy, data are less conclusive. However practical advice would favor waiting for 3-6 months after cessation of endocrine therapy before attempting conception [30]. A similar time period should be applied for patients receiving trastuzumab for which prior maternal exposure has not been shown to affect fetal outcome, at least in the short term [31].

\section{For the Mother?}

In the past, mammary exposure during pregnancy to very high levels of ovarian hormones, pituitary prolactin, and placental lactogens justified the recommendation not to become pregnant after BC [32]. Pregnancy age and parity appear to be synergistic, with high parity $(\geq 5)$ and young age ( $\leq 20$ years) at first birth associated with the greatest reduction in lifetime $\mathrm{BC}$ risk [33]. Several hypotheses have been postulated for the protective effect of pregnancy: full-term pregnancy through the related hormone cascade i) induces terminal differentiation of the mammary gland which becomes less susceptible to tumorigenesis, ii) promotes enhanced capability for DNA repair in mammary cells, iii) activates genes controlling differentiation and programmed cell death, and iv) imprints in the breast epithelium a specific and permanent genomic signature of pregnancy which is long-term protective [34]. There is also recent evidence in rodents suggesting a decrease in mammary stem cells, the targets for transformation, with early parity [35], which could be the basis for a woman's lifetime risk reduction.

\section{Could Pregnancy after Breast Cancer Be Protective?}

The best available modern evidence suggests that pregnancy after BC does not increase a woman's risk of recurrence, and in fact may even confer a protective effect [25, 36-38]. In several population-based retrospective studies where patients were matched for age, disease stage, and year of diagnosis, the relative risk of death was lower for women who conceived after BC than for those who did not. In 2 of these studies, overall survival results were statistically significantly in favor of the cohort that became pregnant $[14,39]$. A recent metaanalysis of 14 such studies, involving 1,244 cases and 18,145 controls, showed a $41 \%$ reduced risk of death in women who became pregnant following BC compared to women who did not [37]. The 'healthy mother bias' suggests that survivors who become pregnant are a self-selected healthier group with a better prognosis [39], but no studies have systematically evaluated the potential for this bias. A recent meta-analysis of 9 studies (1,089 pregnant women, 13,051 matched-controls), corrected for the healthy mother effect by conducting a separate analysis of low-risk patients and matching cases to controls on the basis of prognostic factors. The analysis showed a statistically higher overall survival among patients who became pregnant compared to controls (hazard ratio for death $0.51,95 \%$ confidence interval $0.42-0.62$ ) [40]. However a main bias and confounding factor is the selection of controls not known to be disease-free at the time the matched case became pregnant. Of note, none of the published trials to date have adjusted for this bias in a robust manner. A recent nested case-control study also examined the physical and mental health of 81 young participants from the WHEL study [41]. The sample included 27 cases who had children after $\mathrm{BC}$ and 54 controls, matched for age and stage at diagnosis. Multilevel analysis did not identify a difference in physical health scores between those who became pregnant and those who did not, suggesting the favorable association between survival and childbearing after $\mathrm{BC}$ not to be related to the healthy mother bias. On the other hand, marginally significant higher mental scores were found in women who became pregnant. While mental health has not been traditionally identified as a component of the healthy mother bias, being an important component of overall health, it should be evaluated in future larger studies.

The aforementioned evidence remains suboptimal, and several key questions remain unanswered, due to i) lack of statistical power of the previously conducted studies; ii) uncertainty regarding the true role of the healthy mother effect; iii) lack of information relating to estrogen receptor (ER) status; iv) uncertainty at what time it is safe to become pregnant; and v) the unclear therapeutic role of induced abortion. Recently, Azim et al. conducted a large multicenter, a prioripowered trial involving 1,207 patients, 333 of whom became pregnant after BC. All patients had a known ER status, and all controls were matched according to age, nodal status, year of diagnosis, and systemic adjuvant therapy. To adjust as much as possible to the 'healthy mother effect', controls were known to be free of relapse for a time interval at least equal to the $\mathrm{BC}$ diagnosis and conception in the pregnant group. The primary end point was the difference in disease-free survival according to ER status with pre-specified endpoints addressing the therapeutic role of induced abortion, safety of pregnancy within 2 years of diagnosis, and safety of breastfeeding. Preliminary results confirm the apparent safety of pregnancy in ER-positive BC patients. The final results are expected to be presented in 2012 .

\section{What about Patients with BRCA1/2 Mutations?}

The few studies examining the association between reproductive history and the risk of BC among BRCA1/2 mutation carriers have led to inconsistent results with respect to age at pregnancy, number of children, and mutated genes [42-44]. A recent retrospective cohort study of 1,601 women (853 with $\mathrm{BC}$ ), who carried a mutation in BRCA1/2, from the International BRCA1/2 Carrier Cohort Study (IBCCS) showed no statistically significant difference in the risk of $\mathrm{BC}$ between parous and nulliparous women. Among parous women, an in- 
creasing number of full-term pregnancies were associated with a statistically significant $14 \%$ decrease in the risk of BC for each additional birth. This association was the same for carriers of BRCA1/2 mutations and was restricted to women aged $>40$ years [45]. No data are available on mutated women with subsequent pregnancies after BC. Overall, these data are reassuring concerning the safety of pregnancy for BRCA1/2 mutation carriers. Hence pregnancy should not be discouraged in this population after comprehensive genetic counseling and adequate psychological support [46]. The possibility, at least in some countries, to undergo pre-implantation genetic diagnosis available to women including those carrying a genetic predisposition to $\mathrm{BC}$ [47], adds new complexity to reproductive decision making in this population and requires new strategies for counseling and psychological support of women and their partners [48].

\section{Is Breastfeeding after Breast Cancer Feasible and Safe?}

Breastfeeding is known to have immediate and long lasting advantages for both infant and mother. A meta-analysis of 47 studies found that breastfeeding reduces the risk of developing BC by $4-5 \%$ per year of lactation [49]. In another study the association was stronger among women with a first-degree relative with $\mathrm{BC}$ [50]. In BRCA1/2 carriers data are conflicting $[51,52]$. In the recent IBCCS study history of breastfeeding was not correlated with the risk of BC [45], but the study was not powered to rule out a possible protective effect.

Women previously treated for $\mathrm{BC}$ face a unique physical and emotional status that might impact their decisions and ability to breastfeed [53]. In a single analysis comparing 25 and 27 BC survivors who had bottle-fed and breastfed their children, respectively, 6 and 1 deaths were reported for the 2 groups [54]. While no formal statistics were conducted due to the limited sample, the results appear reassuring. Further data are under evaluation from an ongoing collaborative trial. To the best of our knowledge, no other prospective or retrospective study has specifically addressed this question. From a feasibility perspective, successful breastfeeding following BC from the ipsilateral breast is in the range of 30\% [54] and may be restricted by surgical approaches (i.e. proximity of the incision to the areola/nipple), or the dose and type of radiotherapy [55-57]. Adequate counseling plays an important role in achieving successful lactation in these women [58, 59] who should also be reassured about the nutritional adequacy of milk production by a single breast [55]. Until further data is available, we believe that there is no need to restrict breastfeeding which is associated with improved maternal quality of life and fetal benefits $[53,60]$.

\section{Conclusion}

Pregnancy after BC is still surrounded by myths and facts which, in the era of improved survival in young women with $\mathrm{BC}$, need to be carefully weighed up and clarified. The information available about the safety and feasibility of pregnancy and breastfeeding after $\mathrm{BC}$ does not provide definitive and unquestionable evidence. The final results of a large international trial will be presented soon, which may answer a lot of currently open questions. However this also is a retrospective trial with limitations regarding quality of data collection and selection bias. Hence we believe the availability of reliable current data from dedicated, prospective, international registers will help the scientific community to better understand this multifaceted presentation and to carefully plan future research in this field. This will be possible only through a global initiative involving both the scientific and the advocacy communities. The Breast International Group and North American Breast Cancer Group (BIG-NABCG) has committed to developing such a prospective data collection of clinical and patient-oriented needs in relation to fertility preservation, treatment-related menopausal symptoms, treatment duration, quality of life, and survivorship. The information will help BC health professionals and patients to prioritize clinical research in this orphan field.

\section{Disclosure Statement}

Both authors declare no conflicts of interest.

\section{References}

1 Horner MJ, Ries LAG, Krapcho M (eds): SEER Cancer Statistics Review, 1975-2006. Bethesda, MD, National Cancer Institute. seer.cancer.gov/ csr/1975_2006/, based on November 2008 SEER data submission, posted to the SEER web site, 2009.

2 Smigal C, Jemal A, Ward E, Cokkinides V, Smith $\mathrm{R}$, Howe HL, Thun M: Trends in breast cancer by race and ethnicity: update 2006. CA Cancer J Clin 2006; 56:168-183.

3 Ventura SJ, Abma JC, Mosher WD, Henshaw SK: Estimated pregnancy rates by outcome for the United States, 1990-2004. National Center for Health Statistics. Natl Vital Stat Rep 2008;56:1-25.
4 Prioux F: Late fertility in Europe: some comparative and historical data. Rev Epidemiol Sante Publique 2005;53:2S3-2S11.

5 Maher J, Macfarlane A: Trends in live births and birthweight by social class, marital status and mother's age, 1976-2000. Health Stat Q 2004;23:34-42.

6 Glinianaia SV, Rankin J, Pless-Mulloli T, Pearce MS, Charlton M, Parker L: Temporal changes in key maternal and fetal factors affecting birth outcomes: a 32-year population-based study in an industrial city. BMC Pregnancy Childbirth 2008;8:3952.
7 Heck KE, Schoendorf KC, Ventura SJ, Kiely JL: Delayed childbearing by education level in the United States, 1969-1994. Matern Child Health J 1997;1:81-88.

8 Matthews TJ, Hamilton BE: Delayed childbearing: more women are having their first child later in life. NCHS Data Brief 2009;21:1-8.

9 Abma JC, Chandra A, Mosher WD, Peterson LS, Piccinino LJ: Fertility, family planning, and women's health: new data from the 1995 National Survey of Family Growth. Vital Health Stat 23 1997;19:1-114. 
10 Klijzing E, Corijn M (eds): Dynamics of Fertility and Partnership in Europe. Insights and Lessons from Comparative Research, vol. 1 and 2. New York and Geneva, United Nations, 2002.

$11 \mathrm{Wu}$ Z: Fertility and Family Surveys in Countries of the ECE Region. Standard Country Report Canada. Economic Studies No. 10. New York and Geneva, United Nations, 1999.

12 Del Mastro L, Catzeddu T, Venturini M: Infertility and pregnancy after breast cancer: current knowledge and future perspectives. Cancer Treat Rev 2006;32:417-422.

13 Kroman N, Jensen MB, Melbye M, Wohlfahrt J, Mouridsen HT: Should women be advised against pregnancy after breast cancer treatment? Lancet 1997;350:319-322.

14 Mueller BA, Simon MS, Deapen D, Kamineni A, Malone KE, Daling JR: Childbearing and survival after breast carcinoma in young women. Cancer 2003;98:1131-1140.

15 Blakely LJ, Buzdarm AU, Lozada JA, Shullaih SA, Hoy E, Smith TL, Hortobagyi GN: Effects of pregnancy after treatment for breast carcinoma on survival and risk of recurrence. Cancer 2004;100:465469.

16 Ives A, Saunders C, Bulsara M, Semmens J: Pregnancy after breast cancer: population based study. BMJ 2007;334:194-198.

17 Kroman N, Jensen MB, Wohlfahrt J, Ejlertsen B; Danish Breast Cancer Cooperative Group: Pregnancy after treatment of breast cancer - a population-based study on behalf of Danish Breast Cancer Cooperative Group. Acta Oncol 2008;47:545549.

18 Partridge AH, Gelber S, Peppercorn J Sampson E, Knudsen K, Laufer M, Rosenberg R, Przypyszny M, Rein A, Winer EP: Web-based survey of fertility issues in young women with breast cancer. J Clin Oncol 2004;22:4174-4183.

19 Dow KH: Having children after breast cancer. Cancer Pract 1994;2:407-413.

20 Gorman JR, Usita PM, Madlensky L, Pierce JP Young breast cancer survivors: their perspectives on treatment decisions and fertility concerns. Cancer Nurs 2011;34:32-40.

21 Gorman JR, Malcarne V, Roesch SC, Madlensky L, Pierce JP: Depressive symptoms among young breast cancer survivors: the importance of reproductive concerns. Breast Cancer Res Treat 2010;123:477-485.

22 Wong-Kim EC, Bloom JR: Depression experienced by young women newly diagnosed with breast cancer. Psychooncology 2005;14:564-573.

23 Camp-Sorrell D: Cancer and its treatment effect on young breast cancer survivors. Semin Oncol Nurs 2009;25:251-258.

24 Mick J, Hughes M, Cohen MZ: Using the BETTER Model to assess sexuality. Clin J Oncol Nurs 2004;8:84-86.

25 Peccatori F, Cinieri S, Orlando L, Bellettini G: Subsequent pregnancy after breast cancer. Recent Results Cancer Res 2008;178:57-67.

26 Gelber S, Coates AS, Goldhirsch A, CastiglioneGertsch M, Marini G, Lindtner J, Edelmann DZ, Gudgeon A, Harvey V, Gelber RD: Effect of pregnancy on overall survival after the diagnosis of early-stage breast cancer. J Clin Oncol 2001;19:16711675

27 Ruddy KJ, Gelber S, Ginsburg ES, Schapira L, Abusief ME, Meyer ME, Partridge AH: Menopausal symptoms and fertility concerns in premenopausal breast cancer survivors: a comparison to age- and gravidity-matched controls. Menopause 2011;18:105-108.
28 Langagergaard V, Gislum M, Skriver MV, Nørgård B, Lash TL, Rothman KJ, Sørensen HT: Birth outcome in women with breast cancer. Br J Cancer 2006:94:142-146.

29 Dalberg K, Eriksson J, Holmberg L: Birth outcome in women with previously treated breast cancer - a population-based cohort study from Sweden. PLoS Med 2006;3:e336.

30 Azim HA Jr, Peccatori FA, de Azambuja E, Piccart MJ: Motherhood after breast cancer: searching for la dolce vita. Expert Rev Anticancer Ther 2011;11:287-298.

31 Azim HA Jr, Metzger-Filho O, de Azambuja E, Loibl S, Focant F, Gresko E, Arfi M, PiccartGebhart M: Pregnancy occurring during or following adjuvant trastuzumab in patients enrolled in the HERA trial (BIG 01-01). Breast Cancer Res Treat 2012;133:387-391.

32 Holleb AI: Breast cancer and pregnancy. CA Cancer J Clin 1965;15:182-183.

33 Albrektsen G, Heuch I, Kvåle G: The short-term and long-term effect of a pregnancy on breast cancer risk: a prospective study of 802,457 parous Norwegian women. Br J Cancer 1995;72:480-484.

34 Russo IH, Russo J: Pregnancy-induced changes in breast cancer risk. J Mammary Gland Biol Neoplasia 2011;16:221-233.

35 Siwko SK, Dong J, Lewis MT, Liu H, Hilsenbeck SG, Li Y: Evidence that an early pregnancy causes a persistent decrease in the number of functional mammary epithelial stem cells - implications for pregnancy-induced protection against breast cancer. Stem Cells 2008;26:3205-3209.

36 De Bree E, Makrigiannakis A, Askoxylakis J: Pregnancy after breast cancer. A comprehensive review. J Surg Oncol 2010;101:534-542.

37 Azim HA Jr, Santoro S, Pavlidis N, et al: Safety of pregnancy following breast cancer diagnosis: a meta-analysis of 14 studies. EJC 2011;47:74-83.

38 Pagani O, Partridge A, Korde L, Badve S, Bartlett J, Albain K, Gelber R, Goldhirsch A: Pregnancy after breast cancer: if you wish, ma'am. Breast Cancer Res Treat 2011;129:309-317.

39 Sankila R, Heinavaara S, Hakulinen T: Survival of breast cancer patients after subsequent term pregnancy: 'Healthy mother effect'. Am J Obstet Gynecol 1994;170:818-823.

40 Valachis A, Tsali L, Pesce LL, Polyzos NP, Dimitriadis C, Tsalis K, Mauri D: Safety of pregnancy after primary breast carcinoma in young women: a meta-analysis to overcome bias of healthy mother effect studies. Obstet Gynecol Surv 2010;65:786-793.

41 Gorman JR, Roesch SC, Parker BA, Madlensky L, Saquib N, Newman VA, Pierce JP: Physical and mental health correlates of pregnancy following breast cancer. Psychooncology 2010;19:517-524.

42 Narod SA, Goldgar D, Cannon-Albright L, Weber B, Moslehi R, Ives E, Lenoir G, Lynch H: Risk modifiers in carriers of BRCA1 mutations. Int J Cancer 1995;64:394-398.

43 Hartge P, Chatterjee N, Wacholder S, Brody LC, Tucker MA, Struewing JP: Breast cancer risk in Ashkenazi BRCA1/2 mutation carriers: effects of reproductive history. Epidemiology 2002;13:255261.

44 Cullinane CA, Lubinski J, Neuhausen SL, Ghadirian P, Lynch HT, Isaacs C, et al.: Effect of pregnancy as a risk factor for breast cancer in BRCA1/BRCA2 mutation carrier. Int J Cancer 2005;117:988-991.

45 Andrieu N, Goldgar DE, Easton DF, Rookus M, Brohet R, Antoniou AC, Peock S, Evans G, Eccles D, Douglas F, Noguès C, Gauthier-Villars M,
Chompret A, Van Leeuwen FE, Kluijt I, Benitez J, Arver B, Olah E, Chang-Claude J: Pregnancies, breast-feeding, and breast cancer risk in the International BRCA1/2 Carrier Cohort Study (IBCCS). JNCI 2006;98:535-544.

46 Friedman LC, Kramer RM: Reproductive issues in women with BRCA mutations. J Natl Cancer Inst Monogr 2005;34:83-86.

47 HFEA Choices and Boundaries - public discussion summary. www.hfea.gov.uk/docs/Choices_and_ boundaries_Report_2006_summary.pdf.

48 Ormondroyd E, Donnelly L, Moynihan C, Savona C, Bancroft E, Evans DG, Eeles R, Lavery S, Watson M: Attitudes to reproductive genetic testing in women who had a positive BRCA test before having children: a qualitative analysis. Eur J Hum Genet 2012;20:4-10.

49 Collaborative Group on Hormonal Factors in Breast Cancer: Breast cancer and breastfeeding: collaborative reanalysis of individual data from 47 epidemiological studies in 30 countries, including 50,302 women with breast cancer and 96,973 women without the disease. Lancet 2002;360:187195.

50 Stuebe AM, Willet WC, Xue F, Michels KB Lactation and incidence of premenopausal breast cancer: a longitudinal study. Arch Intern Med 2009;169:1364-1371.

51 Jernstrom H, Lubinski J, Lynch HT, Ghadirian P, Neuhausen S, Isaacs C, Weber BL, Horsman D, Rosen B, Foulkes WD, Friedman E, GershoniBaruch R, Ainsworth P, Daly M, Garber J, Olsson H, Sun P, Narod SA: Breast-feeding and the risk of breast cancer in BRCA1 and BRCA2 mutation carriers. J Natl Cancer Inst 2004;96:10941098.

52 Tryggvadottir L, Olafsdottir EJ, Gudlaugsdottir S, Thorlacius S, Jonasson JG, Tulinius H, Eyfjord JE: BRCA2 mutation carriers, reproductive factors and breast cancer risk. Breast Cancer Res 2003;5: R121-128.

53 Gorman JR, Usita PM, Madlensky L, Pierce JP: A qualitative investigation of breast cancer survivors' experiences with breastfeeding. J Cancer Surviv 2009:3:181-191.

54 Azim HA Jr, Bellettini G, Gelber S, Peccatori FA: Breastfeeding after breast cancer: if you wish, madam. Breast Cancer Res Treat 2009;114:7-12.

55 Moran MS, Colasanto JM, Haffty BG, Wilson LD, Lund MW, Higgins SA: Effects of breast-conserving therapy on lactation after pregnancy. Cancer J 2005; 11:399e 403.

56 Schnitt SJ, Goldwyn RM, Slavin SA: Mammary ducts in the areola: implications for patients undergoing reconstructive surgery of the breast. Plast Reconstr Surg 1993;92:1290-1293.

57 Tralins AH: Lactation after conservative breast surgery combined with radiation therapy. Am J Clin Oncol 1995;18:40-43.

58 Peccatori FA, Azim HA Jr: Pregnancy in breast cancer survivors: a need from proper counselling. Breast 2009;18:337e8.

59 Camune B, Gabzdyl E: Breast-feeding after breast cancer in childbearing women. J Perinat Neonat Nurs 2007;21:225-233.

60 Azim HA Jr, Bellettini G, Liptrott SJ, Armeni ME, Dell'Acqua V, Torti F, Di Nubila B, Galimberti V, Peccatori F: Breastfeeding in breast cancer survivors: pattern, behaviour and effect on breast cancer outcome. Breast 2010;19:527-531. 